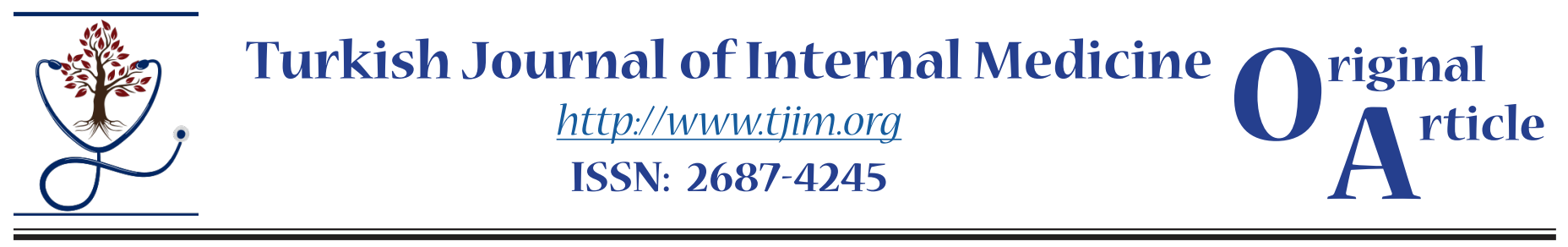

\title{
Effectiveness and Reliability of Splenectomy in Chronic Immune Thrombocytopenia
}

\author{
Mustafa Narmanli ${ }^{1}$ (D), Vildan Gursoy ${ }^{2}$ (D), Ridvan $\mathrm{Ali}^{3}$ (D), Yilmaz Ozen ${ }^{4}$ (D) \\ ${ }^{1}$ Department of Surgery, Medicabil Hospital, Bursa, Turkey \\ ${ }^{2}$ Department of Hematology, University of Health Sciences, Bursa Yuksek Ihtisas Training \& Research Hospital, Bursa, Turkey \\ ${ }^{3}$ Department of Hematology, Bursa Uludag University, Bursa, Turkey \\ ${ }^{4}$ Department of Surgery, Bursa Uludag University, Bursa, Turkey
}

\begin{abstract}
Introduction: Splenectomy is markedly effective treatment modality at early period in adult chronic immune thrombocytopenia (ITP). Long-term outcomes are still controversial. The aim of this study was to determine long-term effectiveness and reliability of splenectomy in ITP and to identify factors influencing on long-term response.

Methods: The study included 100 ITP patients who underwent splenectomy in our general surgery department. Parameters including gender, age, platelet count, comorbid diseases, antiplatelet antibody positivity and longterm effect of medical treatment on response to splenectomy were considered.

Results: Owing to advances in treatment protocols, ITP has become a more benign disease and need for splenectomy has been decreased. However, splenectomy is a highly effective in second-line treatment.

Conclusions: Based on our results, it was seen that open or laparoscopic splenectomy with low morbidity and mortality rates is an appropriate treatment modality for long-term control of chronic ITP in cases requiring splenectomy. Age and postoperative platelet count were identified as significant prognostic and predictive factors for long-term response to splenectomy.
\end{abstract}

Turk J Int Med 2020;2(3):73-77 DOI: $\underline{10.46310 / \text { tjim.767946 }}$

Keywords: splenectomy, chronic immune thrombocytopenia, ITP

\section{Introduction}

Chronic immune thrombocytopenia (ITP) is an acquired disorder which develops due to reduction in lifespan of platelets as a result of early destruction in reticuloendothelial system, particularly in spleen, because of autoantibodies against platelets, and progresses with thrombocytopenia (platelet count $<100 \times 10^{9} / \mathrm{L}$ ). Based on severity of thrombocytopenia, it may often manifest with mucocutaneous bleeding and less frequently with visceral or life-threatening hemorrhages. ${ }^{1,2}$ In addition, fatigue and decreased quality of life can be seen in symptomatic patients.

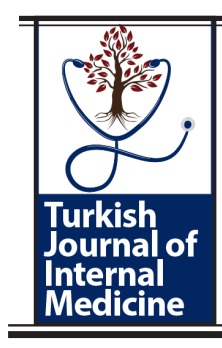

Received:July 10,2020;Accepted:July 26,2020; Published Online: July 29,2020 
In adults, annual incidence is $3.3 / 100,000$ while prevalence is $9.5 / 100,000$ for primary ITP indicating that is not an infrequent disease. ${ }^{3-5}$ The ITP primarily involves women at childbearing age (female:male ratio $=3: 1$ ). It is most commonly seen between 15 and 40 years of age. Its incidence as well as rate of diagnosis in asymptomatic patients has been increased over time. ${ }^{2,6}$ Although investigations on pathophysiology of ITP have been intensified in recent years, its pathogenesis could not be fully elucidated. Major mechanisms addressed are abnormal anti-platelet antibodies, impaired megakaryopoiesis and $\mathrm{T}$ cell-mediated platelet damage and different mechanisms can play role in each patient. ${ }^{7-9}$

The ITP is a condition which may be lifethreatening and annual risk for fatal bleeding ranges from $0.4 \%$ to $13 \%$ based on age. ${ }^{2}$ Although peripheral platelet count is most important marker for bleeding risk, many studies has demonstrated inconsistent results at varying platelet counts. The degree of thrombocytopenia does not necessarily correlate with risk for bleeding. No bleeding is observed in some patient with severe thrombocytopenia while serious bleeding may occur in patients with milder thrombocytopenia. The need for treatment can vary among individuals and is determined by clinical presentation. Corticosteroids are first-line therapy in cases requiring treatment. The goal of treatment is to achieve safe platelet counts to prevent severe bleeding. Splenectomy may be considered as second-line treatment in cases refractory to corticosteroid therapy. Eighty percent of patients respond to splenectomy. The treatment response is persistent in $66 \%$ of responders and no additional treatment is required for at least 5 years. Partial or transient response is observed in those with incomplete response while $14 \%$ of patients are refractory and response will disappear over time. ${ }^{1,2,10,11}$ Additional treatment options include intravenous immunoglobulin (IVIG), high-dose dexamethasone, azathioprine, interferon-alpha $(\mathrm{IFN}-\alpha)$, vincristine and other immunomodulatory agents. In recent years, novel thrombopoietin (TPO) receptor antagonists have become an effective treatment option. However, their use is limited by severe adverse events such as rebound thrombocytopenia ( $10 \%$ reduction in platelet count compared to baseline), increased reticulin fiber in bone marrow and thrombotic complications after withdrawal of drug. As similar to other treatment modalities, decision and recommendation of splenectomy is an individualized process based on age, disease duration, comorbid conditions, effectiveness of steroid therapy, side effects and the patient's preference. ${ }^{2,11}$

\section{Material and Methods}

This retrospective study was conducted on 100 patients with available data who underwent splenectomy with diagnosis of ITP at General Surgery Department of Uludag University, School of Medicine between 1980 and 2004. We extracted data regarding age at presentation, platelet count at presentation, autoantibody positivity, scintigraphy and sonography results, comorbid conditions, hematological parameters, response to medical treatment, adverse events, splenectomy indication and time to splenectomy from patient files. We also assessed preoperative platelet count, vaccination status, preparation therapies at critical platelet counts, age at surgery, type of surgery, minimum and maximum platelet counts within 72 hours after surgery and postoperative morbidity and mortality. Early response was defined as response at month one after surgery while the response was classified as complete, partial and unresponsive. Third-line therapeutic interventions were identified in unresponsive patients and in those with partial response or relapse.

\section{Statistical analysis}

All statistical analyses were performed using SPSS for Windows version 10.01 (SPPS Inc, 1989-1999). Following parameters were used for comparisons between groups: 1-Mean and standard deviation as descriptive statistics for quantitative variables; 2- Kaplan-Meier test for time to relapse and stability duration; 3-Chi-square test to compare rates; 4-Ordinal logistic regression analysis to assess effects of several factors on long-term outcomes and to identify critical age threshold. A p value $<0.05$ was considered as significant while a $\mathrm{p}$ value $<0.01$ as significant on highest degree. 


\section{Results}

The study included 100 patients (22 men and 78 women) who underwent splenectomy with diagnosis of chronic ITP and had minimum follow-up of 12 months. Mean age at presentation was $34.1 \pm 1.4$ years (15-79). The ITP diagnosis was made by symptoms of bleeding as mucocutaneous bleeding being most common while it was made incidentally by exclusion of all other factors causing thrombocytopenia. There was at least one systemic disorder (e.g. hypertension, diabetes mellitus, coronary artery disease, chronic obstructive pulmonary disease) in 21 patients at time of presentation. Mean platelet count at presentation was $17,945 \pm 1,225 \times 10^{9} / \mathrm{L}$ and antiplatelet autoantibody was positive in 22 patients at time of presentation. All patients underwent bone marrow biopsy prior to splenectomy. Bone marrow biopsies resulted in normocellular bone marrow with increased megakaryocytes. Accessory spleen was detected in 2 patients on scintigraphy while splenomegaly in 2 patients on sonography.

Prednisolone as first-line treatment was given to all patients other than one patient declined medical treatment and 2 patients received danazol after declining steroid therapy. In addition to steroid therapy, IVIG was given to 11 patients with critical platelet counts. The splenectomy indications included refractoriness to steroid and other medical therapies in 47 patients, need for highdose steroid therapy and adverse events related to long-term steroid use (Cushingoid appearance, uncontrolled hyperglycemia, neuropathy, myopathy, osteoporosis, gastric bleeding, lung abscess) in 51 patients and declination of medical therapy in 2 patients.

Mean time from medical therapy to splenectomy was $9.4 \pm 1.9$ months (2-168) and all patients received pneumococcal and $\mathrm{Hib}$ vaccines at least 2 weeks before splenectomy. Mean preoperative platelet count was $83,887 \pm 6,574 \times 10^{9} / \mathrm{L}\left(14-330 \times 10^{9} / \mathrm{L}\right)$. Preoperative and perioperative platelet infusions were performed in patients with platelet count $<50 \times 10^{9} / \mathrm{L}$ and IVIG was given to 22 patients before surgery. Mean postoperative 1st day platelet count was $362,849 \pm 25,665 \times 10^{9} / \mathrm{L}$. Ecchymosis or subcutaneous hematoma was developed in 3 patients while pneumonia in 2 patients, superficial wound site infection in 1 patient, epistaxis in 1 patient and intra-abdominal abscess in one patient after surgery. One patient underwent surgery due to intra-abdominal bleeding on the postoperative hour 8. One patient died due to pneumonia developed on the day 7 after surgery.

Mean follow-up after splenectomy was $70.4 \pm 4.9$ months (12-284). The patient with partial response, relapse or no response received steroid and thirdline treatment regimens. No splenectomy-related infection, sepsis or life-threatening abnormality was observed at long-term. All cases showed early response with complete response in 87 patients and partial response in 12 patients. One patient died. Mean time to relapse was $29.5 \pm 9.5$ months (1-156). Of 18 patients with relapse, complete response was achieved in 10 and partial response in 7 patients. One patient was unresponsive. To assess effectiveness and reliability of splenectomy at early and late period, the effects of age, gender, autoantibody positivity, response to medical treatment, time to splenectomy and postoperative platelet counts were addressed with literature data.

Mean age at presentation was 33.2 \pm 3.6 years whereas mean platelet count was $22,288 \pm 20,055 \times 10^{9} / \mathrm{L}$; mean preoperative platelet count was $85,077 \pm 20,055 \times 10^{9} / \mathrm{L}$; mean age was $35 \pm 4$ years at time of surgery. Eleven relapses were observed within first year while no relapse was observed at period of 12-24 months (Table 1).

Low-dose steroid trial was performed in all patients with relapse or those requiring treatment despite partial remission; however, only 5 patients responded to low-dose steroid therapy $(0.5 \mathrm{mg} /$ $\mathrm{kg}$ /day), all of which achieved complete response. Dose escalation was required in 9 patients and complete response could not been achieved.

Table 1: Number of cases and time of relapse

\begin{tabular}{lcccccc}
\hline Time of relapse & $\begin{array}{c}\mathbf{0 - 1 2} \\
\text { Months }\end{array}$ & $\begin{array}{c}\mathbf{1 2 - 2 4} \\
\text { Months }\end{array}$ & $\begin{array}{c}\mathbf{2 4 - 3 6} \\
\text { Months }\end{array}$ & $\begin{array}{c}\mathbf{3 6 - 4 8} \\
\text { Months }\end{array}$ & $\begin{array}{c}\text { 48-60 } \\
\text { Months }\end{array}$ & $>$-60 Months \\
\hline Number of cases & 11 & 0 & 3 & 1 & 1 & 2 \\
\hline
\end{tabular}


Multi-drug therapy was given to 11 patients while 2 patients shifted to azathioprine and partial response persistent in both patients. The refractory patient was lost during follow-up. At long-term, there was complete response in 85 patients, partial response in 13 patients and no response in one patient. In 72 patients, postoperative platelet count remained above $150,055 \times 10^{9} / \mathrm{L}$ and none required medical treatment.

Patients responsive to splenectomy were significantly younger and critical age threshold was estimated to be 37 years in ordinal logistic regression test. It was found that long-term response had highly significant association with age, postoperative platelet count and presence of comorbid disease $(p<0.01)$. No significant association was found for response to steroid, presence of autoantibody and time from medical treatment to splenectomy $(p>0.05)$. Table 2 presents distribution of patients according to parameters evaluated and rates of early and late responses. One month after the operation, the response is considered an early response and the response was defined as complete response (CR), partial response (PR) and unresponsive (UR). The response 12 months after the operation was accepted as a late response (Table 2).

\section{Discussion}

Although chronic ITP is a condition which can be difficult to control, surgical team as well as hematologists are involved the treatment of ITP. Since spleen plays role in both antibody formation and platelet destruction, the destruction is reduced via splenectomy by removing major organ where antibody-coated platelets are up-taken and destructed. Another effective mechanism is that splenectomy allows a significant reduction in total lymphoid mass ( $25 \%$ of which is at spleen) where anti-platelet antibody is generated. Thus, splenectomy remains to be valid therapeutic option in second-line treatment in cases refractory to immunosuppressive treatment or those requiring high doses of steroids. ${ }^{12,14}$

The ITP can affect individuals from all ages; however, it is more commonly seen between puberty and 50 years of age. It is generally seen after 40 years of age and has peak about 30 years of age. ${ }^{13}$ It predominantly affects women at childbearing age. In the literature, female: male ratio varies from 1.7 to 3.0. In our study, female: male ratio was found as 3.5 .

The signs and symptoms are highly variable ranging from mild mucosal bleeding to serious hemorrhages such as intracranial bleeding.

Table 2: Response and variables influencing on response

\begin{tabular}{|c|c|c|c|c|c|c|c|c|}
\hline & & \multicolumn{3}{|c|}{ Early Response } & \multirow[t]{2}{*}{ Relapse } & \multicolumn{3}{|c|}{ Late period } \\
\hline & & CR & PR & Death & & CR & PR & UR \\
\hline \multirow{3}{*}{ Age } & $\begin{array}{l}\leq 37 \mathrm{y} \\
\mathrm{n}: 64\end{array}$ & 59 & 5 & 0 & 7 & 59 & 4 & 1 \\
\hline & $\begin{array}{l}>37 y \\
\mathrm{n}: 36\end{array}$ & 28 & 7 & 1 & 5 & 26 & 9 & 0 \\
\hline & $\begin{array}{l}\text { Female } \\
\mathrm{n}: 78\end{array}$ & 70 & 7 & 1 & 13 & 68 & 9 & 0 \\
\hline Gender & $\begin{array}{l}\text { Male } \\
\mathrm{n}: 22\end{array}$ & 17 & 5 & 0 & 5 & 17 & 4 & 1 \\
\hline \multirow{2}{*}{$\begin{array}{l}\text { Postoperative } \\
\text { platelet count }\end{array}$} & $\begin{array}{l}<300 \times 10^{9} / \mathrm{L} \\
\text { n: } 50\end{array}$ & 38 & 11 & 1 & 11 & 37 & 11 & 1 \\
\hline & $\begin{array}{l}\geq 300 \times 10^{9} / \mathrm{L} \\
\text { n: } 50\end{array}$ & 49 & 1 & 0 & 7 & 48 & 2 & 0 \\
\hline \multirow{2}{*}{ Comorbidity } & $\begin{array}{l}\text { Exist } \\
\mathrm{n}: 21\end{array}$ & 15 & 5 & 1 & 3 & 14 & 6 & 0 \\
\hline & $\begin{array}{l}\text { None } \\
\mathrm{n}: 79\end{array}$ & 72 & 7 & 0 & 15 & 71 & 7 & 1 \\
\hline \multirow{2}{*}{$\begin{array}{l}\text { Response to steroid } \\
\text { therapy }\end{array}$} & $\begin{array}{l}\text { Responsive } \\
\mathrm{n}: 51\end{array}$ & 46 & 5 & 0 & 12 & 41 & 9 & 1 \\
\hline & $\begin{array}{l}\text { Refractory } \\
\text { n: } 47\end{array}$ & 39 & 7 & 1 & 6 & 43 & 3 & 0 \\
\hline \multirow{2}{*}{$\begin{array}{l}\text { Time from medical } \\
\text { treatment to } \\
\text { splenectomy }\end{array}$} & $\begin{array}{l}<6 \text { months } \\
\text { n: } 64\end{array}$ & 56 & 7 & 1 & 11 & 56 & 7 & 0 \\
\hline & $\begin{array}{l}\geq 6 \text { months } \\
\mathrm{n}: 36\end{array}$ & 31 & 5 & 0 & 7 & 29 & 6 & 1 \\
\hline \multirow{2}{*}{$\begin{array}{l}\text { Autoantibody } \\
\text { positivity }\end{array}$} & $\begin{array}{l}\text { Positive } \\
\text { n: } 22\end{array}$ & 20 & 2 & 0 & 3 & 18 & 4 & 0 \\
\hline & $\begin{array}{l}\text { Negative } \\
\text { n: } 78\end{array}$ & 67 & 10 & 1 & 15 & 67 & 9 & 1 \\
\hline
\end{tabular}

CR: complete response, PR: partial response, UR: unresponsive 
Although hemorrhage is rarely seen in general unless there is severe thrombocytopenia, degree of thrombocytopenia does not necessarily correlate with risk for bleeding. Based on previous studies, risk for bleeding is lower in ITP patients when compared to patients with thrombocytopenia and hypo-regenerative bone marrow. This is explained by the fact that, in ITP, circulating platelets are younger; thus, more active in hemostasis. In our study, the patients most commonly presented with mucocutaneous bleeding; followed by those diagnosed incidentally. In Western studies, patients were most commonly diagnosed incidentally, which can be explained by sociocultural level of society and development level of healthcare systems. ${ }^{2,415}$ Despite development level of medicine today, ITP diagnosis can only be made by excluding other causes and factors leading thrombocytopenia. In our study, in addition to other screenings tests, autoantibody screening and bone marrow aspiration were performed in all patients and autoantibody positivity was detected in 22 patients. Sonography evaluation and scintigraphy scan must be performed in all patients scheduled for surgery. Splenomegaly is observed in $3 \%$ of patients on sonography while accessory spleen is seen in $2-13 \%$ of patients on scintigraphy. In our study, splenomegaly was detected in 2 patients by sonography while accessory spleen in 2 patients by scintigraphy. Failure to identify accessory spleen during surgery is major cause of unresponsiveness to surgical treatment. ${ }^{1,11,16,17}$ Thus, screening accessory spleen before surgery will improve success of surgical treatment.

In general, complete remission rate ranges from $53 \%$ to $75 \%$ by initial treatment with steroids. ${ }^{18}$ In our study, all patients underwent splenectomy were refractory to steroid therapy or experienced relapse following steroid. In the treatment of ITP, role of splenectomy is based on more than 80 years of experience and it is only treatment option with known curative effects in majority of patients although different remission rates were reported in different series. In the literature, response rate for splenectomy is $80-85 \%$ in early period and 50 $80 \%$ in late period ${ }^{1,2,11,14,15}$; in our study, response rate was $87 \%$ and $85 \%$, respectively. Available data indicate that splenectomy achieves complete and persistent response in two-third of ITP patients refractory to initial treatment. In a meta-analysis including 2,623 patients, complete response was achieved in $65 \%$ while partial response in $22 \%$ of cases after splenectomy. ${ }^{19}$ In addition, remission was persistent in almost all cases achieved response with splenectomy.

Although there are different opinions about timing of splenectomy, in a consensus report published in 2019, it is recommended to delay splenectomy for 12 or 24 months due to likelihood of remission and stabilization after diagnosis. ${ }^{20}$ However, splenectomy before 12 months can be considered in cases in which severe and symptomatic thrombocytopenia persist despite initial steroid therapy and are at higher risk for bleeding. The time from medical therapy to splenectomy differs among different clinics and studies; and it was found as $9.42 \pm 1.91$ months (2168 ) in our study. However, it was found that time from medical treatment to splenectomy had no significant effect on outcome..$^{1,2,21}$

Although splenectomy-related morbidity and mortality rates vary according to factors such as surgical technique employed, age, preoperative platelet count, they have been reported as $9-12 \%$ and $0.2-1 \%$ in different series, respectively. ${ }^{19}$ In recent years, in parallel to advances in minimally invasive surgery, it has become a more preferable method with minimal morbidity and shorter length of hospital stay. In a review including 3,000 splenectomy cases, morbidity and mortality rates were found to be lower in laparoscopy group compared to laparotomy group (morbidity; $9.6 \%$ vs. $12.9 \%$ and mortality; $0.2 \%$ vs. $1 \%$ ). The complete response is observed within first two weeks after splenectomy and platelet count can increase immediately after splenectomy in some cases. ${ }^{22}$ In our study, 93 patients underwent conventional splenectomy while 7 patients underwent laparoscopic splenectomy. In recent years, laparoscopic splenectomy was performed in more cases due to increased experience; thus, splenectomy-related morbidity and mortality rates were markedly decreased. By improved surgical experience, laparoscopic splenectomy has become choice of surgical method by taking patient characteristics into account.

Major complications include surgical complications and infections in splenectomy. During follow-up, 6 patients died due to ITP and treatments related to ITP, including 2 patients with bleeding and 4 patients with infection. ${ }^{2}$ In another study, 27 of 245 patients (11\%) died 
during study period and cause of death was ITP-related hemorrhage in 3 patients $(1.2 \%)$, post-splenectomy sepsis in one patient $(0.4 \%)$. Remaining deaths were found to be unrelated with ITP or treatment. ${ }^{1,23}$ To minimize risk for infection after splenectomy, patients should be vaccinated against Streptococcus pneumoniae, Hemophilus influenzae and Neisseria meningitidis at least two weeks before surgery.

Varying relapse rates have been reported following splenectomy and relapse is generally seen within first years with decreased likelihood of relapse over time. ${ }^{1,2,14,15}$ Although relapse is more commonly seen in emergent splenectomy in particular, accessory spleen is detected in 10$18 \%$ of the patients refractory to splenectomy or experience relapse after splenectomy. In our study, no accessory spleen was detected on scintigraphy in 18 patients with relapse. ${ }^{24,25}$ Mean time to relapse was 29,556 \pm 9 months (1-156) and relapse developed within first year in 11 patients.

Splenectomy decision or recommendation is an individualized process, which is affected by patient age, comorbid conditions and psychology and sociocultural level of patients. Splenectomy decision is challenging in all aspects; thus, patients who will benefit from splenectomy, extent of expected benefit and risks should be identified before surgery. ${ }^{1,2}$ Although many studies investigated predictive and prognostic factors for splenectomy in ITP, only age at splenectomy was found as positive prognostic factor in some studies. $^{14,26,27}$ In our study, effects of gender, comorbid condition, age at splenectomy, time from medical treatment to splenectomy, presentation, preoperative and postoperative platelet counts, steroid response and autoantibody positivity were evaluated at long-term after splenectomy. It was found that age at splenectomy and postoperative platelet count had highly significant positive effect on outcome while presence of comorbid condition had highly significant negative effect on outcome. Age $<37$ years and postoperative platelet count $>300 \times 10^{9} / \mathrm{L}$ were determined as major positive prognostic and predictive factors.

\section{Conclusion}

In conclusion, chronic ITP is the hematological disorder in which feasibility of both medical and surgical treatments have been studied most intensively. In current treatment algorithm, steroid therapy is first choice; however, splenectomy is the only curative treatment with complete response rates of $87 \%$ and $85 \%$ at early and late period in patients with insufficient response to steroid therapy. Age and postoperative platelet count are major prognostic and predictive factors for longterm outcomes.

\section{Conflict of interest}

The authors declared that there are no potential conflicts of interest with respect to the research, authorship, and/or publication of this article.

\section{References}

1. British Committee for Standards in Haematology General Haematology Task Force. Guidelines for the investigation and management of idiopathic thrombocytopenic purpura in adults, children and in pregnancy. Br J Haematol. 2003 Feb;120(4):574-96. doi: 10.1046/j.1365-2141.2003.04131.x.

2. Stasi R, Provan D. Management of immune thrombocytopenic purpura in adults. Mayo Clin Proc. 2004 Apr;79(4):504-22. doi: 10.4065/79.4.504.

3. Fogarty PF. Chronic immune thrombocytopenia in adults: epidemiology and clinical presentation. Hematol Oncol Clin North Am. 2009 Dec;23(6):1213-21. doi: 10.1016/j.hoc.2009.08.004.

4. Schoonen WM, Kucera G, Coalson J, Li L, Rutstein M, Mowat F, Fryzek J, Kaye JA. Epidemiology of immune thrombocytopenic purpura in the General Practice Research Database. Br J Haematol. 2009 Apr;145(2):23544. doi: 10.1111/j.1365-2141.2009.07615.x.

5. Moulis G, Palmaro A, Montastruc JL, Godeau B, Lapeyre-Mestre M, Sailler L. Epidemiology of incident immune thrombocytopenia: a nationwide populationbased study in France. Blood. 2014 Nov 20;124(22):330815. doi: 10.1182/blood-2014-05-578336.

6. George JN, Raskob GE. Idiopathic thrombocytopenic purpura: A concise summary of the pathophysiology and diagnosis in children and adults. Semin Hematol. 1998 Jan;35(1 Suppl 1):5-8.

7. Shulman NR, Marder VJ, Weinrach RS. Similarities between known antiplatelet antibodies and the factor responsible for thrombocytopenia in idiopathic purpura. Physiologic, serologic and isotopic studies. Ann N Y Acad Sci. 1965 Jun 30;124(2):499-542. doi: 10.1111/j.17496632.1965.tb18984.x.

8. Khodadi E, Asnafi AA, Shahrabi S, Shahjahani M, Saki $\mathrm{N}$. Bone marrow niche in immune thrombocytopenia: a focus on megakaryopoiesis. Ann Hematol. 2016 Oct;95(11):1765-76. doi: 10.1007/s00277-016-2703-1.

9. Olsson B, Andersson PO, Jernås M, Jacobsson S, Carlsson B, Carlsson LM, Wadenvik H. T-cell-mediated cytotoxicity toward platelets in chronic idiopathic thrombocytopenic purpura. Nat Med. 2003 Sep;9(9):11234. doi: $10.1038 / \mathrm{nm} 921$. 
10. Ismet A, Irfan K, Emin K, AlI EM, Ramazan U, Mustafa $\mathrm{B}$, Onur O. Splenectomy results in patients with idiopathic thrombocytopenic purpura: 10 years of experience in Turgut Ozal Medical Center. Clin Lab Haematol. 2004 Jun;26(3):211-4. doi: 10.1111/j.1365-2257.2004.00602.x.

11. Schwartz J, Leber MD, Gillis S, Giunta A, Eldor A, Bussel JB. Long term follow-up after splenectomy performed for immune thrombocytopenic purpura (ITP). Am J Hematol. 2003 Feb;72(2):94-8. doi: 10.1002/ajh.10253.

12. Beardsley DS. ITP in the 21st century. Hematology Am Soc Hematol Educ Program. 2006:402-7. doi: 10.1182/ asheducation-2006.1.402.

13. Pamuk GE, Pamuk ON, Baslar Z, Ongören S, Soysal T, Ferhanoglu B, Aydin Y, Ulkü B, Aktuglu G, Akman N. Overview of 321 patients with idiopathic thrombocytopenic purpura. Retrospective analysis of the clinical features and response to therapy. Ann Hematol. 2002 Aug;81(8):436-40. doi: 10.1007/s00277-002-0488-X.

14. Vianelli N, Galli M, de Vivo A, Intermesoli T, Giannini B, Mazzucconi MG, Barbui T, Tura S, Baccaranion M; Gruppo Italiano per lo Studio delle Malattie Ematologiche dell'Adulto. Efficacy and safety of splenectomy in immune thrombocytopenic purpura: long-term results of 402 cases. Haematologica. 2005 Jan;90(1):72-7.

15. Zoghlami-Rintelen C, Weltermann A, Bittermann C, Kyrle PA, Pabinger I, Lechner K, Wenzl E. Efficacy and safety of splenectomy in adult chronic immune thrombocytopenia. Ann Hematol. 2003 May;82(5):290-4. doi: 10.1007/s00277-002-0550-8.

16. Cohen YC, Djulbegovic B, Shamai-Lubovitz O, Mozes B. The bleeding risk and natural history of idiopathic thrombocytopenic purpura in patients with persistent low platelet counts. Arch Intern Med. 2000 Jun 12;160(11):1630-8. doi: 10.1001/archinte.160.11.1630.

17. Velanovich V, Shurafa M. Laparoscopic excision of accessory spleen. Am J Surg. 2000 Jul;180(1):62-4. doi: 10.1016/s0002-9610(00)00417-7.

18. Diagnosis and treatment of idiopathic thrombocytopenic purpura: recommendations of the American Society of Hematology. The American Society of Hematology ITP Practice Guideline Panel. Ann Intern Med. 1997 Feb 15;126(4):319-26. doi: 10.7326/0003-4819-126-4199702150-00010.

19. Kojouri K, Vesely SK, TerrellDR, George JN. Splenectomy for adult patients with idiopathic thrombocytopenic purpura: a systematic review to assess long-term platelet count responses, prediction of response, and surgical complications. Blood. 2004 Nov 1;104(9):2623-34. doi: 10.1182/blood-2004-03-1168.

20. Provan D, Arnold DM, Bussel JB, Chong BH, Cooper N, Gernsheimer T, Ghanima W, Godeau B, GonzálezLópez TJ, Grainger J, Hou M, Kruse C, McDonald V, Michel M, Newland AC, Pavord S, Rodeghiero F, Scully M, Tomiyama Y, Wong RS, Zaja F, Kuter DJ. Updated international consensus report on the investigation and management of primary immune thrombocytopenia. Blood Adv. 2019 Nov 26;3(22):3780-817. doi: 10.1182/ bloodadvances.2019000812.

21. Vesely SK, Perdue JJ, Rizvi MA, Terrell DR, George JN. Management of adult patients with persistent idiopathic thrombocytopenic purpura following splenectomy: a systematic review. Ann Intern Med. 2004 Jan 20;140(2):112-20. doi: 10.7326/0003-4819-140-3200402030-00012.

22. Wu JM, Lai IR, Yuan RH, Yu SC. Laparoscopic splenectomy for idiopathic thrombocytopenic purpura. Am J Surg. 2004 Jun;187(6):720-3. doi: 10.1016/j. amjsurg.2003.11.032.

23. Portielje JE, Westendorp RG, Kluin-Nelemans HC, Brand A. Morbidity and mortality in adults with idiopathic thrombocytopenic purpura. Blood. 2001 May 1;97(9):2549-54. doi: 10.1182/blood.v97.9.2549.

24. Gunes I, Yilmazlar T, Sarikaya I, Akbunar T, Irgil C. Scintigraphic detection of splenosis: superiority of tomographic selective spleen scintigraphy. Clin Radiol. 1994 Feb;49(2):115-7. doi: 10.1016/s0009-9260(05)83452-x.

25. Kinuya K, Matano S, Nakashima H, Taki S. Scintigraphic prediction of therapeutic outcomes of splenectomy in patients with thrombocytopenia. Ann Nucl Med. 2003 Apr;17(2):161-4. doi: 10.1007/BF02988457.

26. Fabris F, Tassan T, Ramon R, Carraro G, Randi ML, Luzzatto G, Moschino P, Girolami A. Age as the major predictive factor of long-term response to splenectomy in immune thrombocytopenic purpura. Br J Haematol. 2001 Mar;112(3):637-40. doi: 10.1046/j.1365-2141.2001.02615.x.

27. Chen CC, Ho CH, Wu TS, Wu JS, You JY, Chau WK, Hsu HC, Gau JP. Predictive prognostic factors after splenectomy in patients with idiopathic thrombocytopenic purpura. Haematologica. 2001 Jun;86(6):663-4. 